\title{
The effects of high-tannin leaf litter from transgenic poplars on microbial communities in microcosm soils
}

\author{
Richard S. Winder ${ }^{1}{ }^{*}$, Josyanne Lamarche ${ }^{2}$, C. Peter Constabel ${ }^{3}$, and Richard C. Hamelin ${ }^{2}$ \\ 1 Pacific Forestry Centre, Canadian Forest Service, Natural Resources Canada, Victoria, BC, Canada \\ ${ }^{2}$ Laurentian Forestry Centre, Canadian Forest Service, Natural Resources Canada, Sainte-Foy, QC, Canada \\ ${ }^{3}$ Centre for Forest Biology, University of Victoria, Victoria, BC, Canada
}

\section{Edited by:}

Tim Daniell, The James Hutton

Institute, UK

\section{Reviewed by:}

Alison Bennett, James Hutton Institute, UK

Sari Timonen, University of Helsinki, Finland

\section{${ }^{*}$ Correspondence:}

Richard S. Winder, Pacific Forestry Centre, Canadian Forest Service, Natural Resources Canada, 506, West Burnside Road, Victoria, BC V8Z 1M5, Canada

e-mail: Richard.Winder@NRCanRNCan.gc.ca
The impacts of leaf litter from genetically modified hybrid poplar accumulating high levels of condensed tannins (proanthocyanidins) were examined in soil microcosms consisting of moss growing on sieved soil. Moss preferentially proliferated in microcosms with lower tannin content; DGGE (denaturing gradient gel electrophoresis) detected increased fungal diversity in microcosms with low-tannin litter. The proportion of cloned rDNA sequences from Actinobacteria decreased with litter addition while Bacteroidetes, Chloroflexi, Cyanobacteria, and $\alpha$-Proteobacteria significantly increased. $\beta$-Proteobacteria were proportionally more numerous at high-tannin levels. Tannins had no significant impact on overall diversity of bacterial communities analyzed with various estimators. There was an increased proportion of $\mathrm{N}$-fixing bacteria corresponding to the addition of litter with lowtannin levels. The addition of litter increased the proportion of Ascomycota/Basidiomycota. Dothideomycetes, Pucciniomycetes, and Tremellomycetes also increased and Agaricomycetes decreased. Agaricomycetes and Sordariomycetes were significantly more abundant in controls, whereas Pucciniomycetes increased in soil with litter from transformed trees ( $P=0.051)$. Richness estimators and diversity indices revealed no significant difference in the composition of fungal communities; PCoA (principal coordinate analyses) partitioned the fungal communities into three groups: (i) those with higher amounts of added tannin from both transformed and untransformed treatments, (ii) those corresponding to soils without litter, and (iii) those corresponding to microcosms with litter added from trees transformed only with a $\beta$-glucuronidase control vector. While the litter from transformed poplars had significant effects on soil microbe communities, the observed impacts reflected known impacts on soil processes associated with tannins, and were similar to changes that would be expected from natural variation in tannin levels.

Keywords: transgenic, tree, forestry, risk assessment, Populus tremuloides, nitrogen cycle

\section{INTRODUCTION}

With increasing global demand for wood products, interest has grown in methods that could potentially provide trees with promising new and desirable traits for the forest products industry. Using genetic modification to enhance valuable traits in trees without compromising desirable genetic background offers an alternative to conventional breeding in this context, by permitting the transfer of genetic material into selected genotypes. Exogenous genes, transferred from unrelated organisms, can confer novel traits such as herbicide, disease, or pest resistance. Research using transgenic methods has been conducted on more than thirty tree species (Peña and Seguin, 2001; Gartland et al., 2003; van Frankenhuyzen and Beardmore, 2004). Poplar is considered a model tree for transgenic transformation because of the wealth of extant information on its genomics (Jansson and Douglas, 2007), its susceptibility to genetic transformation (Morse et al., 2004), and its rapid growth, making it amenable for use by for the pulp and paper industry (Stanton et al., 2002).

Concerns about potential risks associated with out-planting genetically modified trees on the landscape have led to regulatory restrictions (bans) on their use in Canada (Hay et al., 2002; van Frankenhuyzen and Beardmore, 2004). While the use of genetically modified trees may not be an immediate human health risk, concerns do arise about the potential impacts of these trees within ecological systems. For example, it has been suggested that transgenic trees might accelerate the development of pest resistance and give rise to new pest dynamics (Hay et al., 2002; Marvier, 2002). Other concerns include the possibility of gene escape (Hay et al., 2002) and the potential for "genetic pollution" of natural populations. These issues are pertinent to the biodiversity of native forest ecosystems, which is considered more valuable than the biodiversity of agro-ecosystems because trees are a particularly long-lived component (Gartland et al., 2003; Halpin et al., 2007). Thus, it is important to pay particular attention to the potential "side-effects" that transgenic trees such as poplar might have on their immediate environment, including the soil environment and its key nutrient cycling microbial communities.

Laboratory, greenhouse, and field studies have largely reported little to no impact of transformation on microbial communities of soils (Hampp et al., 1996; Kaldorf et al., 2002; Pasonen et al., 2005; 
Lamarche and Hamelin, 2007; Newhouse et al., 2007; Seppänen et al., 2007; Oliver et al., 2008; Stefani et al., 2009, 2010; Lottman etal., 2010; Lamarche etal., 2011), although some have found significant changes in particular microbial groups (LeBlanc et al., 2007; Andreote et al., 2009). These responses to genetic modifications occur within a wider context of variable natural genotypic influences on microbial communities. For example, in common garden experiments comparing naturally occurring genotypes of Populus angustifolia and Populus fremontii, heritable genotypic variation was found to cause up to $75 \%$ of the variation in microbial biomass and $70 \%$ of the variation in community composition (Schweitzer et al., 2008).

Although leaf litter is a prime avenue through which trees may impact their soil environment, there has been limited study focused on the environmental impacts of litter from transgenic forest trees. In one field study, Vauramo et al. (2006) found that fungal biomass was similar in leaf litter from controls versus that from silver birch trees transformed with a chitinase gene. Given the ecological importance of leaf litter, much further work is needed to delineate the potential impacts of litter from transformed trees in natural forests and forestry situations.

This study addresses the potential impacts of leaf litter from transgenic hybrid poplar (Populus tremula $\times$ tremuloides) that accumulate high concentrations of proanthocyanidins (condensed tannin) due to over-expression of the PtMYB134 transcriptional regulator (Mellway et al., 2009). Depending on growth conditions, these transgenics can accumulate 5-50-fold higher levels of leaf tannins compared to control plants. The tannins found in the leaf litter of poplars significantly influence decomposition and other soil processes (Mansfield, 1999; Schweitzer et al., 2004; Madritch et al., 2006). Tannin levels in poplar are variable but genetically determined, and are implicated in diverse ecological adaptations including defense against pests and pathogens, as well as other stress responses (Witham et al., 2006; Constabel and Lindroth, 2010). Many tannins have antimicrobial properties (Scalbert, 1991); in poplar, they may defend against fungal pathogens (Miranda et al., 2007; Holeski et al., 2009). In general, tannins are reported to have a number of potential modes of action against microbes, including inhibition of microbial binding to biomaterials (Howell et al., 1998), and inhibition of enzymatic activity (e.g., Adamczyk et al., 2009). Tannins found in leaf litter are associated with reduced activity of hydrolases ( $\beta$-glucosidase, $N$-acetyl-glucosaminidase), peroxidase, and acid phosphatase in soils (Joanisse et al., 2007; Triebwasser et al., 2012) and decrease net $\mathrm{N}$-mineralization and gross ammonification while increasing $\mathrm{N}$-immobilization (e.g., Bradley et al., 2000); proanthocyanins and other condensed tannins were observed to be no less labile or inhibitory than hydrolysable tannins (Kraus et al., 2004). In Populus balsamifera growing in the Alaskan taiga, Schimel et al. (1998) attributed major changes in soil N-cycling to the secondary compounds found in poplar leaves; poplar litter reduced $\mathrm{N}$-fixation, decomposition, and $\mathrm{N}$-mineralization, while increasing $\mathrm{N}$-immobilization. Some reports indicate that this inhibition of N-cycling can be qualified by the molecular weight of condensed tannins, the vegetative history of the soil, and by the microbial community present (Fierer et al., 2001; Triebwasser et al., 2012); however, research in other types of plant litter has found some of these influences to be inconsistent (Norris et al., 2011).

The general objective of this study was to develop a model microcosm system for testing impacts of transgenic litter in microcosms, as a tool for both risk analysis and environmental modeling. Microcosms are reported to be useful in assessing the effects or potential risks associated with genetically modified organisms on a smaller scale (Bolton et al., 1991; Krimsky et al., 1995; Pasonen et al., 2005), and the effects of leaf litter on nutrient dynamics (Madritch and Hunter, 2003).

Our specific goal was to study the impacts of leaf litter from genetically modified hybrid poplar accumulating high proanthocyanidin levels on microbial communities in very simplified microcosm soils supporting live moss. In the absence of extensive roots, mycorrhizal networks, and mobile organisms, microbial populations in the microcosms were restricted to immediately adjacent nutrient resources. This simplification was performed in order to increase resolution for baseline processes and limit the fluctuation of $\mathrm{C}$ and potentially confounding effects from nutrient subsidies (Teuben and Verhoef, 1992; Machinet et al., 2009; McGuire and Treseder, 2009). We hypothesized that the microbial communities associated with litter from poplar with high-tannin levels would be significantly different in terms of both structure and abundance of predominant species or groups. We also predicted that these changes would reflect the known impacts on soil processes associated with tannins.

\section{MATERIALS AND METHODS TRANSGENIC POPLAR LITTER}

Transgenic poplars used in this study were hybrid poplar (Populus tremula $\times$ tremuloides) over-expressing the PtMYB134 proanthocyanidin regulator under control of the double 35S promoter, described by Mellway et al. (2009). Control plants consisted of the parental genotype (clone INRA 353-38; Leple et al., 1995) and plants over-expressing a $\beta$-glucuronidase reporter (GUS vector; GV) gene as a transgenic control (Mellway et al., 2009). Leaf litter from two typical transgenic lines expressing high levels of proanthocyanidin (HP lines: MYB 134-62 and MYB 134-48), the GV line (GUS 41), and the parental wild-type line (PT) was collected as leaves senesced and abscised from 1.5-m saplings. Leaves were stored in darkness at $20^{\circ} \mathrm{C}$. In order to acquire sufficient litter for the experiment, equal amounts of leaves collected from the two $\mathrm{HP}$ lines were combined into one pooled lot.

\section{SOIL COLLECTION AND MICROCOSM ASSEMBLY}

Soil was collected in November 2006 from a mature plantation of non-transgenic Populus trichocarpa and Populus trichocarpa $\times$ deltoides [TxD] hybrid clones (16 year-old) located at the Scott Paper Nursery, Harrison Mills, BC, Canada within an area designated "Espacement Trial 1988." The soil at this location is acidic (pH 5.6) and alluvial, classified as Monroe Clay Loam, with organic matter and $\mathrm{N}$ comparable to upland soils, concentration of $\mathrm{P}$ and $\mathrm{Ca}$ in the $\mathrm{A}_{0}$ horizon, and other elements evenly distributed (Kelley and Spilsbury, 1939). Prior to the plantation, the area was used to pasture cows. The understorey grass at the plantation was previously cut several times, with the last mowing occurring 2 years prior to soil sampling. Within the espacement trial, poplar clones (Populus 
trichocarpa var. "Blom”, clones “B.C.," “TxD 49-177," “TxD 50197," and “TxD 44-143”; Quinsey et al., 1991) had been replicated along transects with spacing treatments ranging from 3.6 to $4.8 \mathrm{~m}$. The Populus trichocarpa clones were derived from poplars indigenous to nearby Chilliwack, B.C. Soil samples were taken using a trowel to excavate ca. $10 \mathrm{~cm}^{2}$ to a depth of ca. $5 \mathrm{~cm}$. The samples were acquired from plots corresponding to four different clones, with rows of trees spaced $4.5 \mathrm{~m}$ apart. The understorey vegetation primarily consisted of various grass species. In each plot, five samples were taken at random points, midway between the rows. Each soil sample was passed through a sieve $(4 \mathrm{~mm})$ and an equal portion from each was added to a single pooled lot; the lot was manually homogenized to form a single composite soil. Moisture of the composite soil was adjusted to ca. $15 \%$ through the addition of $\mathrm{dH}_{2} \mathrm{O}$ and then divided into four portions corresponding to poplar litter derived from the three different sources (HP, GV, PT) plus a soil control.

A completely randomized experimental design was employed to assay the soil in microcosms. Leaf lots were separately mulched through a 4 -mm sieve, and litter was added to three separate lots of the composite soil $(1.3 \% \mathrm{w}: \mathrm{w})$ and thoroughly mixed by hand to create a soil-litter mix. Microcosms (three replications per leaf litter type) were constructed by adding ca. $100 \mathrm{~g}$ of soillitter mix to a sterile 250-mL Erlenmeyer flask, plugging the flask with a foam cap, and covering the flask with aluminum foil; all steps were performed using aseptic technique. Prior to sealing the microcosms, $0.5 \mathrm{~g}$ of soil-litter mix was removed from each 100 -g replication, pooled to form a non-incubated control, and stored at $-20^{\circ} \mathrm{C}$ for subsequent analysis of initial microbial communities. The microcosms were weighed and placed in random, assigned positions in a growth chamber within a $3 \times 4$ grid spaced ca. $10 \mathrm{~cm}$ apart. The microcosms were incubated at $20^{\circ} \mathrm{C}$ with a 16-h diurnal photoperiod for $60 \mathrm{~d}$. Microcosms were weighed daily, and sterile water was added to each flask with a sterile pipette to maintain the initial flask weight. Germinating seedlings of any plants other than mosses were removed with sterile forceps. At the end of incubation, the proliferation of mosses in each microcosm was visually estimated, as the differences in moss growth were readily apparent. Moss growth was ranked on a scale of 1-4, where " 1 " corresponded to less than $5 \%$ coverage of the soil surface, " 2 " corresponded to 5-33\% coverage of the soil surface, " 3 " corresponded to $33-90 \%$ coverage of the soil surface, and " 4 " corresponded to complete coverage of the soil surface. There was no variance in the results, therefore they were excluded from statistical analysis.

After incubation, soil-litter mix was stored at $4^{\circ} \mathrm{C}$ prior to subsequent analysis. For each soil/litter lot, the initial proanthocyanidin content of leaves (GV: $22.65 \mathrm{mg} \mathrm{g}^{-1}$; PT: $45.45 \mathrm{mg} \mathrm{g}^{-1}$; HP: $109.95 \mathrm{mg} \mathrm{g}^{-1}$ ) was confirmed by extraction with $80 \%$ aqueous $\mathrm{MeOH}$ and assaying tannins according to the $\mathrm{BuOH}-\mathrm{HCl}$ method of Porter etal. (1986). Purified tannin from Populus tremuloides was used as a standard.

\section{DNA EXTRACTION}

After an incubation period of $60 \mathrm{~d}$, duplicate 0.15 -g soil-litter mix samples were removed from each microcosm and each control lot with a sterile metal scoop. The samples were extracted using
UltraClean $^{\circledR}$ Soil DNA kits (MoBio Laboratories, Carlsbad, CA, USA), according to manufacture's instructions. To reduce the PCR inhibition noted in preliminary trials, the isolated DNA was precipitated by adding a mixture of 0.1 volume of $7.5 \mathrm{M} \mathrm{NH}_{4} \mathrm{OAc}$ buffer and $30 \mu \mathrm{g}(6 \mu \mathrm{l})$ of Co-precipitate (Bio-Line USA Inc., Taunton, MA, USA), and 2 volumes of cold 95\% EtOH to the samples. The samples were incubated at room temperature for at least $30 \mathrm{~min}$ prior to being centrifuged at $13,000 \times \mathrm{g}$. Precipitated pellets were washed with $70 \% \mathrm{EtOH}$, air-dried, and re-suspended in TE buffer, $\mathrm{pH}$ 8.0. Extracted DNA was visualized through electrophoresis with a $1 \%$ agarose EtBr gel and imaged using a transillumination system (Chemigenius Q with GeneSnap software, Syngene USA, Frederick, MD, USA). Duplicate DNA samples were pooled and quantified using a spectrophotometer (Nanodrop-1000, Nanodrop Technologies, Wilmington, DE, USA).

\section{PCR-DGGE}

A preliminary check of DNA diversity was performed with one sample from each microcosm after 30 and $60 \mathrm{~d}$ incubation, using PCR-DGGE. The primers used to amplify $16 \mathrm{~S}$ and $18 \mathrm{~S}$ rDNA regions are listed in Table 1. All incubations and PCR steps were performed in a T-gradient thermocycler (Biometra $\mathrm{GmbH}$, Goettingen, Germany). Prior to PCR steps, samples were heated at $96^{\circ} \mathrm{C}$ for $3 \mathrm{~min}$. and then cooled to $80^{\circ} \mathrm{C}$ before addition of $5 \mu \mathrm{l}$ of Master Mix with Gold TAQ (Invitrogen Canada Inc., Burlington, ON, Canada). For 16S rDNA amplification, PCR was performed according to the protocol of Fortin et al. (2004), while PCR for $18 \mathrm{~S}$ rDNA was performed according to the protocol of Vainio et al. (2005). PCR products were visualized by electrophoresis in a $1.8 \%$ agarose $\mathrm{EtBr}$ gel and imaging with the transillumination system. Denaturing gradient gel electrophoresis (DGGE) was performed using a D-Code ${ }^{\mathrm{TM}}$ Universal Mutation Detection system (BioRad Laboratories Ltd., Mississauga, ON, Canada) according to the manufacturer's instructions, with some modifications. PCR products were loaded onto an $8 \%(\mathrm{w} / \mathrm{v})$ acrylamide/bisacrylamide (37:5:1) gel with a denaturing gradient ranging between 10 and $60 \%$ in $1 \times$ TAE buffer $(40 \mathrm{mM}$ Tris, $20 \mathrm{mM}$ acetic acid and $1 \mathrm{mM}$ EDTA at $\mathrm{pH} 8.3$ ). Electrophoresis was continued for $3.5 \mathrm{~h}$ at $60^{\circ} \mathrm{C}$ and $200 \mathrm{~V}$. Gels were stained using $\mathrm{SYBR}^{\circledR}$ Gold (Invitrogen) and visualized using the transillumination system.

\section{ISOLATION AND SEQUENCING OF rDNA CLONES}

In order to determine the predominant $16 \mathrm{~S}$ and $18 \mathrm{~S}$ rDNA sequences present in the microcosm soils, rDNA clones were amplified and sequenced from the soil DNA extracts mentioned above. To ensure completion of sequencing within available resources, we restricted the analysis to treatments with added litter, and extracts from soil before litter addition and incubation. Extracts from microcosms incubated without litter were excluded from the analysis. Amplification of $16 \mathrm{~S}$ rDNA from the DNA extracts was performed in $25 \mu \mathrm{l}$ reaction volumes containing water, $1 \times$ buffer, $1.5 \mathrm{mM} \mathrm{MgCl}_{2}, 200 \mu \mathrm{M}$ dNTPs, $0.4 \mu \mathrm{M}$ of each primers (Table 1), $1 \mathrm{U}$ of Platinum Taq polymerase (Invitrogen), and $1 \mu \mathrm{l}$ of DNA template. The reaction was performed in the Tgradient thermocycler (Biometra $\mathrm{GmbH}$, Goettingen, Germany) 
Table 1 | Primers used to amplify $16 \mathrm{~S}$ and 18S rRNA genes of microbes in soil microcosms.

\begin{tabular}{|c|c|c|c|}
\hline Primer & Primer sequence & Assay & Reference \\
\hline 16S F: $341-357^{*}$ Forward & 5'CCT ACG GGA GGC AGC AG P - 3' & PCR-DGGE & Fortin et al. (2004) \\
\hline 16S R: $758-740$ Reverse & 5' CTA CCA GGG TAT CTA ATC C - 3' & & \\
\hline $18 S$ FF390 Forward & $5^{\prime}$ CGA TAA CGA ACG AGA CCT - 3' & & Vainio et al. (2005) \\
\hline 18S FR $1 * *$ Reverse & 5' AI CCA TTC AAT CGG TAI T - 3' & & \\
\hline 16S M13 F2 Forward & $5^{\prime}$ GTA AAA CGA CGG CCA GT - 3' & Clone library & Anonymous (2001) \\
\hline 16S M13 R2 Reverse & $5^{\prime}$ AAC AGC TAT GAC CAT G - 3' & & \\
\hline $18 S$ nu-ssu-0817 Forward & $5^{\prime}$ TTA GCA TGG ATT ATT RRA ATA GGA - 3' & & Borneman and Hartin (2000) \\
\hline 18S FR1 Reverse & 5' AIC CAT TCA ATC GGT AIT - 3' & & Vainio et al. (2005) \\
\hline
\end{tabular}

*For DGGE, the GC clamp added to the 5 ' end of the primer was 5' GCG GGC GGG GCG GGG GCA CGG GGG GCG CGG CGG GCG GGG CGG GGG 3'.

* For DGGE, the GC clamp added to the 5' end of the primer was 5' CCC CCG CCG CGC GCG GCG GGC GGG GCG GGG GCA CGG GCC G3'.

with the following thermal protocol: initial denaturation of $94^{\circ} \mathrm{C}$ for $2 \mathrm{~min}, 35$ cycles of $94^{\circ} \mathrm{C}$ for $1 \mathrm{~min}$., $55^{\circ} \mathrm{C}$ for $30 \mathrm{~s}, 72^{\circ} \mathrm{C}$ for $1 \mathrm{~min}$., and a final extension of $72^{\circ} \mathrm{C}$ for $5 \mathrm{~min}$. Amplification of $18 \mathrm{~S}$ rDNA from the DNA extracts was performed in $25 \mu \mathrm{l}$ reaction volumes containing $1 \mathrm{mg} / \mathrm{ml}$ non-acetylated BSA, $1 \times$ buffer, $3 \mathrm{mM} \mathrm{MgCl}_{2}, 200 \mu \mathrm{M}$ dNTPs, $0.5 \mu \mathrm{M}$ of each primers (Table 1), $1 \mathrm{U}$ of Diamond DNA polymerase (Bioline), $1 \times \mathrm{Hi}^{-}$ Spec Additive (Bioline), and $1 \mu \mathrm{l}$ of DNA template. The reaction was performed with the following thermal protocol: initial denaturation of $95^{\circ} \mathrm{C}$ for $2 \mathrm{~min}$., 30 cycles of $94^{\circ} \mathrm{C}$ for $45 \mathrm{~s}, 55^{\circ} \mathrm{C}$ for $40 \mathrm{~s}, 57^{\circ} \mathrm{C}$ for $10 \mathrm{~s}, 72^{\circ} \mathrm{C}$ for $1 \mathrm{~min}$., and a final extension of $72^{\circ} \mathrm{C}$ for $10 \mathrm{~min}$.

The PCR products were cloned into vectors using the QIAGEN PCR Cloning Kit (Qiagen Inc., Valencia, CA, USA) according to the manufacturer's protocol for $1,000 \mathrm{bp}$ sequences (fivefold molar excess, $65 \mathrm{ng}$ product, $30 \mathrm{~min}$. incubation in ligation mixture). Successful transformants were picked, re-suspended in sterile $\mathrm{dH}_{2} \mathrm{O}$, and boiled (at $100^{\circ} \mathrm{C}$ for $5 \mathrm{~min}$ ) prior to PCR amplification. A total of 2304 clones were produced (twenty-four 96-well plates). Amplifications were performed using the same PCR process again, using $1 \mu \mathrm{l}$ of boiled colonies as the DNA template. PCR products generating a single band of $\sim 1210 \mathrm{bp}(16 \mathrm{~S})$ or $\sim 980 \mathrm{bp}$ (18S) on the agarose gel were considered suitable candidates for sequencing. A total of 1,088 clones ( 448 for $16 \mathrm{~S}$ rDNA and 640 for $18 \mathrm{~S}$ rDNA) were submitted to McGill University and Genome Quebec Innovative Centre for sequencing, by single primer extension with the forward primer used in the PCR (Table 1). Samples that failed to provide a return sequence or returned sequences with a Phred quality score of less than 50 were excluded from analysis.

\section{BACTERIAL AND FUNGAL COMMUNITY ANALYSES}

Sequences (16S and 18S rDNA datasets separately) were edited and assembled with Sequencher v4.6 (GeneCodes, Ann Arbor, MI, USA). Libraries were analyzed using Bellerophon (Huber et al., 2004) and potentially chimeric sequences were excluded from the data sets. The final 16S rDNA and 18S rDNA datasets included 430 and 622 sequences, respectively. Sequences were aligned with MUSCLE software v3.6 (Edgar, 2004). For each leaf litter treatment, rarefaction curves, Chao richness estimator as well as Shannon diversity index were computed with MOTHUR software v1.15.0 (Schloss et al., 2009) using 3 and 2\% distance levels for $16 \mathrm{~S}$ and $18 \mathrm{~S}$ rDNA, respectively. Sequence alignments were converted in distance matrices using the DNADIST program (Jukes-Cantor as substitution model) from the PHYLIP package to produce neighbor-joining trees with MEGA version 4 (Tamura et al., 2007).

A phylum (bacteria) or class (fungi) classification was performed to identify major groups of microorganisms. For bacteria, we used the Ribosomal Database Project (RDP) Classifier tool to assign each sequence to a phylum using a naïve Bayesian rRNA classifier (Wang et al., 2007), with $80 \%$ similarity being the determining threshold. For fungi, consensus sequences of each operational taxonomic unit (OTU) were identified with the closest sequences found in the NCBI GenBank database using BLASTN (Altschul et al., 1990).

Separate principal coordinate analyses (PCoA) were performed for bacterial and fungal communities using UniFrac (accessed January 12, 2011; Lozupone and Knight, 2005). The PCoA used normalized abundance weights, treating each sample equally instead of treating each unit of branch equally.

\section{ANALYSES OF NUTRIENT CYCLING BACTERIAL GROUPS}

Because proanthocyanidins affect N-cycling, phosphorus solubilization, and cellulose degradation, a more detailed taxonomic analysis was performed to categorize $16 \mathrm{~S}$ rDNA sequences using matches to known or putative nitrogen-fixing or nitrifying microbes. Identities were ascribed to the sequences using BLASTN; the highest-ranking, most specific taxa at the $98-100 \%$ similarity level were used to designate sequences. This information was compared against the available literature to categorize organisms as $\mathrm{N}$-fixing, nitrifying, phosphorus-solubilizing, or cellulose- ( $\beta$ glucoside-) degrading. Taxa higher than species were categorized with these functional attributes if a substantial majority of species were reported to possess the attribute. 


\section{STATISTICAL ANALYSES}

Analyses of variance for Chao richness estimator and Shannon diversity index were performed in R v2.9 (R Development Core Team, 2005) using the Vegan (R-Forge) package. The potential effects of leaf litter treatment and incubation time on the abundance of each bacterial phylum and fungal class were analyzed with a Poisson linear regression, performed with Statistica 8.0 (C) (Statsoft Inc., Tulsa, OK, USA). The data from the DGGE experiment and also from categorization of sequences pertaining to nutrient cyclers was also subjected to analysis of variance using Statistica 8.0, where Levene's test was used to check for heterogeneity of variance and the Newman-Keuls test was used to determine significant differences. The proportion of nutrient cycling groups versus treatment was analyzed with the same software using multivariate analysis of variance (MANOVA) and the preceding tests for statistical assumptions.

\section{NUCLEOTIDE SEOUENCE ACCESSION NUMBERS}

The rDNA sequences obtained from cDNA were deposited in the GenBank database. Accession numbers are KC663721-KC664150 for 16S rDNA and KC664151-KC664772 for 18S rDNA.

\section{RESULTS}

\section{MACROSCOPIC OBSERVATIONS}

At the end of the 60-d incubation, it became clear that moss preferentially proliferated in microcosms with lower tannin content $(\mathrm{GV}$, PT, and litter-free controls), versus scant growth in microcosms with higher tannin content (HP). The mosses were identified from morphology and chloroplast rRNA genes as a mixture of Ceratodon purpureus (99\% similarity), Climacium americanum (99\% similarity), and a member of the Bryales (93\% similarity to several species in the Bryales). Chloroplast sequences detected in the GV (KC663735, KC663739), PT (KC663842, KC663928), and HP (KC664033) soil samples corresponded to the moss taxa. Representative microcosms are shown in Figure 1. Moss coverage was visually estimated to be $<1 \%$ for each HP soil sample (category 1 ), ca. $5 \%$ for each PT soil sample (category 2), ca. 50\% for each GV soil samples (category 3 ), and total for each soil sample incubated without leaf litter (category 4).

\section{DENATURING GRADIENT GEL ELECTROPHORESIS}

The results of the DGGE assay of $18 \mathrm{~S}$ sequences showed a significant overall effect of litter type, incubation period, and their interaction (Tables 2 and 3 ). The number of distinct $18 \mathrm{~S}$ sequences detected significantly increased with time for controls and all litter types except HP, where the number of bands remained the same. Microcosms with PT litter experienced a significantly $(P<0.000001, F=27.3321, d f=3,24)$ greater increase, but the other litter types were not significantly different from controls. For DGGE of 16S rDNA, there was insufficient distinction between profuse numbers of diffuse bands to permit a clear comparative analysis.

\section{CLONED rDNA SEQUENCES - BACTERIAL DIVERSITY}

The slope of the sequence-based rarefaction curves was similar for all treatments (Figure 2A), indicating that soil bacterial diversity was comparable between all treatments. None of the

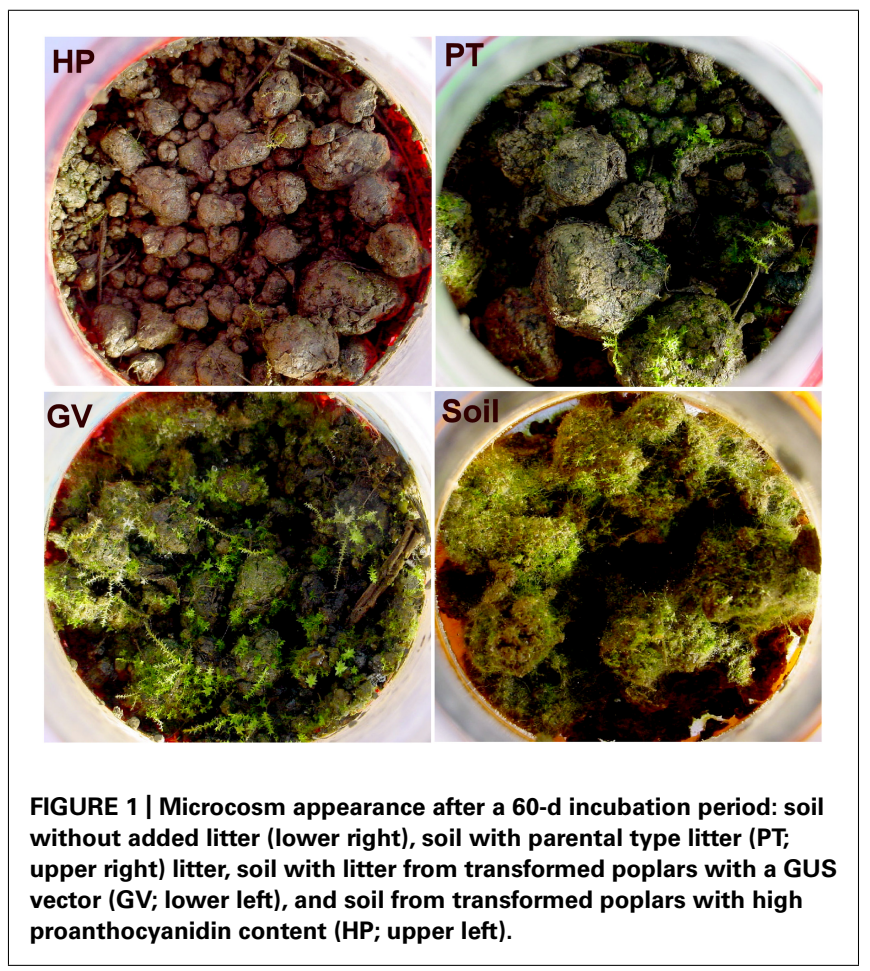

Table 2 | Summary of results for statistical tests used in analyses of variance for poplar litter experiments.

\begin{tabular}{lllll}
\hline Experiment & Effect & df & \multicolumn{1}{l}{$\boldsymbol{F}$} & $\boldsymbol{p}$ \\
\hline \multirow{2}{*}{ 18S DGGE } & Litter type & 3,24 & 27.3321 & $<0.000001$ \\
& Incubation period & 2,24 & 52.0689 & $<0.000001$ \\
& Interaction & 6,24 & 9.0058 & 0.001370 \\
16S rDNA & Treatment (N-fixer) & 3,8 & 7.38679 & 0.010808 \\
& Treatment (Nitrifier) & 3,8 & 0.63665 & 0.612176 \\
& Treatment (Cellulose & 3,8 & 1.14348 & 0.388684 \\
& degrader) & & & \\
& Treatment (Phosphate & 3,8 & 1.02327 & 0.432077 \\
& solubilizer) & & & \\
& & & & \\
\end{tabular}

a A preliminary Levene's test for these data indicated significant $(d f=11$, $F=6.127553, p=0.000423$ ) heterogeneity of variance which data transformations were unable to resolve. The analysis was therefore performed using a Weighted Least Squares method, with ANOVA weighted by inverse of the variance for each group.

rarefaction curves reached saturation, indicating that we did not capture all the bacterial diversity that was present. Overall, the proportion of Actinobacteria decreased between the control soil and all other treatments, whereas the proportion of Bacteroidetes, Chloroflexi, Cyanobacteria, and $\alpha$-Proteobacteria significantly increased (Table 4). The only significant difference between the PT, $\mathrm{GV}$, and HP treatments corresponded to $\beta$-Proteobacteria, which had proportionally higher numbers in HP and PT soils compared to GV soils (Table 4). 
Table 3 | Mean number of 18S rDNA DGGE bands detected in DNA extracted from microcosm soils with poplar litter, after incubation for up to $60 \mathrm{~d}$.

\begin{tabular}{lll}
\hline Litter type & Incubation period (d) & Mean number of bands \\
\hline Parental type & 0 & $2.3 \mathrm{ADIJ}$ \\
& 30 & $11.0 \mathrm{BEGH}$ \\
& 60 & $9.3 \mathrm{BCFGH}$ \\
Gus Vector & 0 & $1.0 \mathrm{AGIJ}$ \\
& 30 & $5.3 \mathrm{BCEFIJ}$ \\
High proanthocyanidin & 0 & $6.0 \mathrm{BCFJ}$ \\
& 30 & $3.0 \mathrm{ADEFIJ}$ \\
None & 60 & $3.0 \mathrm{ADEFIJ}$ \\
& 0 & $3.0 \mathrm{ADFIJ}$ \\
& 30 & $1.7 \mathrm{ADFIJ}$ \\
& 60 & $7.7 \mathrm{BCH}$ \\
\end{tabular}

Means in the same column followed by the same letter are not significantly different $(p>0.05)$ according to the Newman-Keuls multiple range test.

The number of OTUs, Chao richness estimator and Shannon diversity index computed for each treatment are displayed in Table 5. The results indicate that neither richness nor diversity was significantly different between the treatments.

The first two axis from the PCoA explained $64.7 \%$ of the variance and the results showed that none of the four treatments had a unique bacterial community, as they all clustered more or less together, indicating that there was no significant impact of any of the treatments on overall bacterial diversity (Figure 3A).

\section{CLONED rDNA SEQUENCES - DIVERSITY OF NUTRIENT CYCLING BACTERIAL GROUPS}

Comparison of treatments in MANOVA produced a significant $(P=0.051, F=7.38679, d f=3,8)$ difference in the proportion of known $\mathrm{N}$-fixers (Tables 2 and 6). Isolated sequences corresponding to taxa that we presumed to be $\mathrm{N}$-fixers included: Aphanizomenon flos-aquae, Azospirillum sp., Bradyrhizobium elkanii, Bradyrhizobium iriomotense, Bradyrhizobium sp., Burkholderia hospita, Calothrix sp., Mezorhizobium australicum, Nordella oligomobilis, Nostoc calcicola, Nostoc ellipsosporum, Phyllobacterium myrsinacearum, Rhodospirillaceae, and Sphingomonas sp. MANOVA did not detect any significant difference between treatments versus the proportion of identifiable nitrifiers (17-21\%), phosphate solubilizers (25-26\%), or cellulose degraders (33-36\%; Tables 2 and 6 ).

\section{CLONED rDNA SEOUENCES - FUNGAL DIVERSITY}

According to the sequence-based rarefaction curves (Figure 2B), the GV treatment had an almost saturated slope, whereas treatment control had the steepest one. This result suggests that even though the sampling effort was similar for all treatments, it did not capture soil fungal diversity to the same extent. At the phylum level,

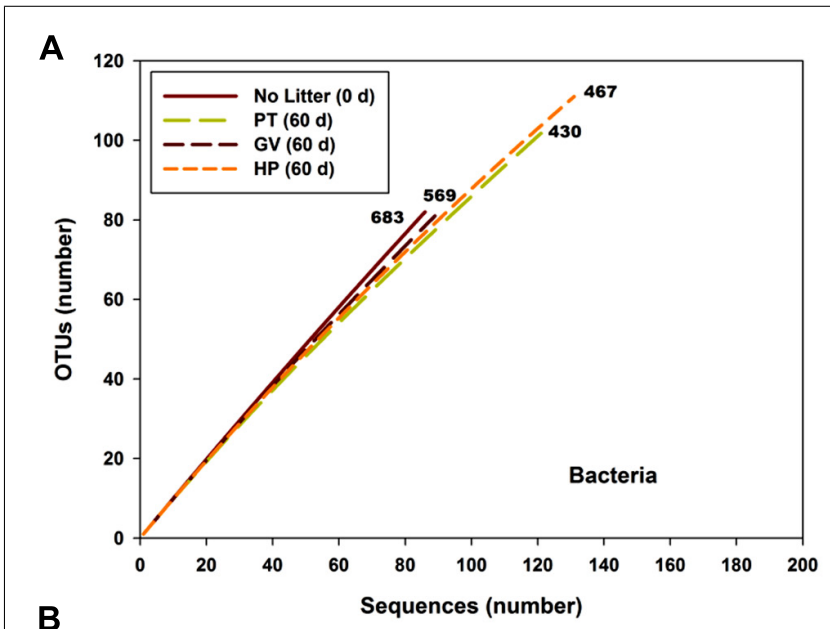

B

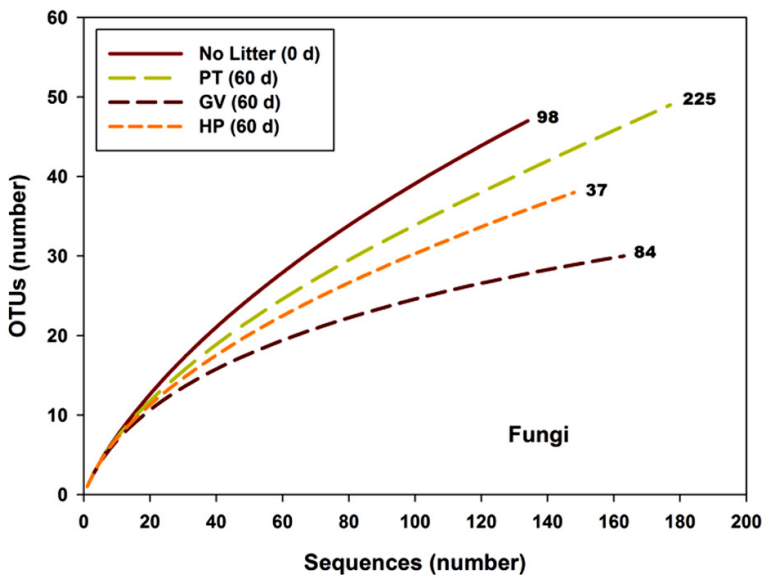

FIGURE 2 | Rarefaction curves for bacterial (A) and fungal (B) sequences vs. OTUs found in microcosms with soil and leaf litter from Populus tremuloides. Curves are shown for soil before incubation (0 d) without added litter (Control), and soil from microcosms incubated for $60 \mathrm{~d}$, with litter either from parental type (PT) saplings or transgenic poplar possessing either a simple GUS vector (GV) or higher expression of proanthocyanidins (HP). Numbers next to curves indicate the Chao richness estimate.

the proportion of Ascomycota/Basidiomycota increased between control and all other treatments, with Ascomycota representing $18 \%$ at control and between 30 and $40 \%$ for 60 -d incubated treatments (Table 7). More specifically, at the class level, Agaricomycetes populations significantly decreased from $42 \%$ to $3-9 \%$, whereas the proportion of Dothideomycetes, Pucciniomycetes, and Tremellomycetes significantly increased; from $13 \%$ to $23-36 \%$ for Dothideomycetes, from $0 \%$ to $0.6-4.7 \%$ for Pucciniomycetes, and from $17 \%$ to $39-47 \%$ for Tremellomycetes (Table 7). There were some significant differences between treatments after the $60-\mathrm{d}$ incubation. Agaricomycetes and Sordariomycetes were significantly more abundant in PT soil than in any other treatment, whereas Pucciniomycetes were nearly in significantly higher proportion in HP soil (Table 7). The Pucciniomycete sequences closely (>95\%) matched the moss parasite Eocronartium muscicola. Table 8 presents the observed richness along with Chao, ACE, and Jackknife richness estimators, and Shannon and Simpson 
Table 4 | Taxonomic classification of 16S rDNA sequences in microcosms with soil and leaf litter from Populus tremuloides.

\begin{tabular}{|c|c|c|c|c|}
\hline & \multicolumn{4}{|c|}{ Mean proportion of sequences ${ }^{a}$} \\
\hline & $\begin{array}{l}\text { PT } \\
(60 d)\end{array}$ & $\begin{array}{l}\mathbf{G V}^{\mathbf{b}} \\
(\mathbf{6 0} \mathbf{d})\end{array}$ & $\begin{array}{l}\text { HP } \\
\text { (60d) }\end{array}$ & $\begin{array}{l}\text { No litter } \\
\text { (0 d) }\end{array}$ \\
\hline Acidobacteria & 23.4 & 19.1 & 13 & 19.8 \\
\hline Actinobacteria & 3.2 & 9 & 9.2 & $24.4^{*}$ \\
\hline Bacteroidetes & 2.4 & 3.4 & 3.8 & $0^{*}$ \\
\hline Chloroflexi & 3.2 & 1.1 & 3.8 & $1.2^{*}$ \\
\hline Cyanobacteria & 8.9 & 4.5 & 9.9 & $0^{*}$ \\
\hline Firmicutes & 0.8 & 0 & 0 & 1.2 \\
\hline Gemmatimonadetes & 1.6 & 1.1 & 1.5 & 2.3 \\
\hline Nitrospira & 0 & 0 & 0 & 1.2 \\
\hline Planctomycetes & 0 & 0 & 1.5 & 1.2 \\
\hline \multicolumn{5}{|l|}{ Proteobacteria } \\
\hline$\alpha$-Proteobacteria & 25.8 & 32.6 & 26 & $15.1^{*}$ \\
\hline$\beta$-Proteobacteria & 5.7 & $1.1^{*}$ & 9.9 & 9.1 \\
\hline$\delta$-Proteobacteria & 8.1 & 11.3 & 8.4 & 3.5 \\
\hline$\gamma$-Proteobacteria & 3.2 & 4.5 & 3 & 3.5 \\
\hline Unclassified Proteobacteria & 2.4 & 0 & 0.8 & 1.2 \\
\hline TM7 & 0 & 0 & 0 & 1.2 \\
\hline Unclassified & 10.5 & 11.2 & 6.9 & 12.8 \\
\hline Verrucomicrobia & 0.8 & 1.1 & 2.3 & 2.3 \\
\hline
\end{tabular}

PT, parental type litter (60 d); GV, GUS vector; HP, high proanthocyanidin content. a Abbreviated soil types are followed by days of incubation.

${ }^{\mathrm{b}}$ The mean in this column marked with an asterisk $\left(^{*}\right)$ is significantly different $(P=0.002)$ than the mean for microcosms with other incubated soils (i.e., treatment affect corresponding to the mean of PT and HP soils in same row) according to Poisson linear regression analysis.

${ }^{\mathrm{C}}$ Means in this column marked with an asterisk $\left(^{*}\right)$ are significantly different $(P<0.002)$ than the mean for microcosms sampled $60 d$ later (i.e., incubation effect corresponding to the mean of other soils in the same row) according to Poisson linear regression analysis.

Table 5 | Diversity of bacterial communities in microcosms with soil and leaf litter from Populus tremuloides.

\begin{tabular}{lll}
\hline Soil type $^{\mathbf{a}}$ & Chao richness estimator & Shannon diversity index \\
\hline PT (60 d) & 569 & 4.55 \\
GV (60 d) & 467 & 4.36 \\
HP (60 d) & 430 & 4.65 \\
No litter (0 d) & 683 & 4.39 \\
\hline
\end{tabular}

a Including days of incubation

PT, parental type litter; GV, GUS vector, HP, high proanthocyanidin content.

diversity indices for each treatment. Analysis of variance performed on richness estimators and diversity indices revealed no significant difference between treatments.

Results obtained from the PCoA (Figure 3B), for which the first two axes explain $71.0 \%$ of the variance within the dataset, partitioned the fungal communities into three groups: one including
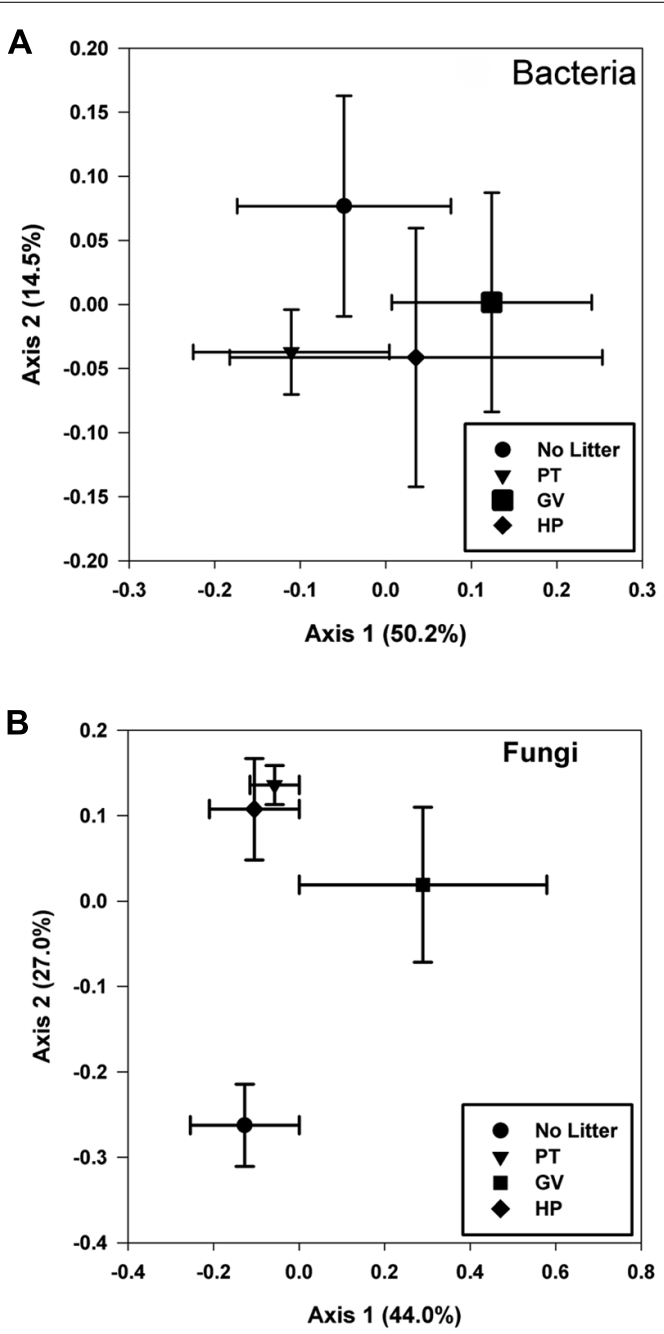

FIGURE 3 | Principal coordinate analyses of bacterial (A) and fungal (B) communities found in microcosms with soil and leaf litter from

Populus tremuloides. Communities correspond to soil in microcosms before incubation ( $0 \mathrm{~d}$ ) and without added litter (Control), and soil from microcosms incubated for $60 \mathrm{~d}$, with litter either from parental type (PT) saplings or transgenic poplar possessing either a simple GUS vector (GV) or higher expression of proanthocyanidins (HP).

those with higher levels of tannin in litter from both PT and HP treatments; another one from the control soil and a separate one from the GV treatment.

\section{DISCUSSION}

We hypothesized that microbial communities associated with poplar litter would be significantly different, in terms of structure and abundance of predominant species or groups, when exposed to poplar litter with elevated tannin levels. This prediction was substantiated for some species and functional groups, but not in all cases for all treatments. For example, the diversity of fungi detected by DGGE increased when low-tannin litter was added to microcosms, but not for addition of high-tannin litter. We attribute this to the proliferation of fungal decomposers in litter with lower condensed tannins, and a lack of fungal growth in litter with higher 
Table 6 | The impact of litter types on the mean proportion of various microbial communities in soil microcosms.

\begin{tabular}{lllll} 
Litter type $^{\mathbf{a}}$ & $\begin{array}{l}\mathbf{N} \text {-fixers } \\
\mathbf{( \% )}^{\mathbf{a}}\end{array}$ & $\begin{array}{l}\text { Nitrifiers } \\
\mathbf{( \% )}^{\mathbf{b}}\end{array}$ & $\begin{array}{l}\text { Cellulose } \\
\text { degraders (\%) }\end{array}$ & $\begin{array}{l}\text { Phosphate } \\
\text { solubilizers (\%) }\end{array}$ \\
\hline PT (60 d) & $5.5 \mathrm{BC}$ & 18.7 & 30.7 & 25.0 \\
GV (60 d) & $7.6 \mathrm{~A}$ & 13.7 & 36.2 & 25.0 \\
HP (60 d) & $5.2 \mathrm{AC}$ & 21.0 & 32.6 & 26.1 \\
None (0 d) & 6.2 BC & 16.8 & 34.1 & 25.4
\end{tabular}

PT, parental type litter; GV, GUS vector; HP, high proanthocyanidin content.

a Including days of incubation.

${ }^{b}$ Means in this column followed by the same letter are not significantly different $(p>0.05)$ according to the Newman-Keuls multiple range test.

${ }^{c} F$ test was not significant $(P>0.05)$.

Table 7 | Taxonomic classification of $18 \mathrm{~S}$ sequences in microcosms with soil and leaf litter from Populus tremuloides.

\begin{tabular}{|c|c|c|c|c|}
\hline & \multicolumn{4}{|c|}{ Mean proportion of sequences ${ }^{a}$} \\
\hline & $\begin{array}{l}\mathrm{PT}^{\mathrm{b}} \\
(60 \mathrm{~d})\end{array}$ & $\begin{array}{l}\text { GV } \\
(60 \mathrm{~d})\end{array}$ & $\begin{array}{l}H^{c} \\
(60 \mathrm{~d})\end{array}$ & $\begin{array}{l}\text { No litter } \\
\text { (0 d) }\end{array}$ \\
\hline Agaricomycetes & $8.7^{*}$ & 3.7 & 3.4 & $41.9^{*}$ \\
\hline Basal fungal lineages & 4.4 & 7.4 & 2.0 & 7.4 \\
\hline Chytridiomycetes & 0.0 & 0.0 & 0.0 & 0.7 \\
\hline Dothideomycetes & 25.7 & 22.7 & 35.6 & $13.2^{*}$ \\
\hline Eurotiomycetes & 1.6 & 0.0 & 0.7 & 0.0 \\
\hline Orbiliomycetes & 0.0 & 1.8 & 0.0 & 0.0 \\
\hline Pucciniomycetes & 1.1 & 0.6 & $4.7^{*}$ & $0.0^{*}$ \\
\hline Sordariomycetes & $13.1^{*}$ & 5.5 & 0.7 & 5.1 \\
\hline Tremellomycetes & 38.8 & 45.4 & 47.0 & $16.9 *$ \\
\hline Unclassified fungi & 2.3 & 1.2 & 0.0 & 2.2 \\
\hline \multicolumn{5}{|l|}{ Others } \\
\hline Metazoa & 4.3 & 9.2 & 2.7 & 8.1 \\
\hline Rhizaria & 0.0 & 2.5 & 1.3 & 4.4 \\
\hline Viridiplantae & 0.0 & 0.0 & 2.0 & 0.0 \\
\hline \multicolumn{5}{|l|}{ Summary } \\
\hline Ascomycetes & 40.4 & 30.1 & 36.9 & $18.4^{*}$ \\
\hline Basidiomycetes & 48.6 & 49.7 & 55.0 & 58.8 \\
\hline Others & 10.9 & 20.2 & 8.1 & 22.8 \\
\hline
\end{tabular}

PT, parental type litter (60d); GV, GUS vector; HP, high proanthocyanidin content. a Abbreviated soil types are followed by days of incubation.

${ }^{\mathrm{b}}$ Means in this column marked with an asterisk (*) are significantly different $(P<0.038)$ than the mean for microcosms with other incubated soils (i.e., treatment effect corresponding to the mean of GV and HP soils in same row) according to Poisson linear regression analysis.

${ }^{\mathrm{C}}$ Means in this column marked with an asterisk (*) are nearly significantly different $(P=0.051)$ than the mean for microcosms with other incubated soils (i.e., treatment effect corresponding to the mean of GV and PT soils in same row) according to Poisson linear regression analysis.

${ }^{\mathrm{d}}$ Means in this column marked with an asterisk $\left({ }^{*}\right)$ are significantly different $(P<0.042)$ than the mean for microcosms sampled $60 \mathrm{~d}$ later (i.e., incubation effect corresponding to the mean of other soils in the same row) according to Poisson linear regression analysis.
Table 8 | Diversity of fungal communities in microcosms with soil and leaf litter from Populus tremuloides.

\begin{tabular}{lll} 
Soil type $^{\text {a }}$ & Chao richness estimator & Shannon diversity index \\
\hline PT $(60$ d) & 225 & 2.99 \\
GV $(60$ d) & 37 & 2.67 \\
HP $(60$ d) & 84 & 2.84 \\
No litter (0 d) & 98 & 3.08
\end{tabular}

$P T$, parental type litter (60 d); GV, GUS vector; HP, high proanthocyanidin content. a Including days of incubation.

tannin levels. In future studies, correlation of fungal DGGE assays with quantitative data from cloned rDNA sequences would help to delineate which species respond to the presence of litter. The PCoA results for fungi also showed that communities in microcosms with litter clustered separately from those without, with the communities in the GV treatment also clustering separately from litter with higher tannin levels. We attributed this to a distinction between the impacts of litter added as a nutritional substrate versus effects of inhibitory higher tannins within that substrate. The attenuation of some fungal rarefaction curves suggested that subtle differences in diversity could be detected with further sampling.

Considered in the context of prior studies, our findings reinforce the notion that impacts of genetic transformations on microbial communities of soils will vary, depending on the plant and the specific transgenes expressed in the plant. Oliver et al. (2008) found no significant effects on bacterial diversity and minor potential effects on the fungal community when assaying poplars over-expressing polyphenol oxidase. Hampp et al. (1996) found that transformation of poplars with hygromycin marker or indoleacetic acid biosynthetic genes did not affect the ability of Amanita muscaria to form mycorrhizae. Results similar to these examples were obtained in work with endochitinase-transformed white spruce; Stefani etal. (2010) did not detect any interference with ectendomycorrhizal Wilcoxina spp. and Lamarche et al. (2011) did not detect any significant impacts of transformation on fungal biomass or community structure in such trees. By contrast, a study of Eucalyptus grandis $\times$ urophylla transformed with the nptII (kanamycin resistance) gene, under control of the pea $L h c b 1-2$ promoter, detected significant changes in $\alpha$ Proteobacteria and Methylobacterium communities. The changes among treatments were comparable in scale to variability in wildtype populations, but some could be specifically attributed to effects of the transformation on soil communities (Andreote et al., 2009). Transformation of silver birch trees with various genes had an impact on the abundance of roots associated with the ectomycorrhizal (EM) fungus Paxillus involutus, through effects on root anatomy. However, no overall effect on the ability to form mycorrhizal relationships was observed (Pasonen et al., 2005; Seppänen et al., 2007).

Field studies have also produced varied results. A study of hybrid poplar (Populus tremula $\times$ tremuloides) with an altered phytohormone profile found no difference in EM colonization and diversity, although one transformed line produced changes in 
the abundances of some EM fungi (Kaldorf et al., 2002). Newhouse et al. (2007) found little effect of transformation with genes for an antimicrobial peptide on colonization rates for EM fungi. Stefani et al. (2009) found no long-term impacts on EM fungal diversity associated with field-deployed poplar transformed with $n p t I I$ marker and GUS reporter genes. Field studies of Bt-transformed white spruce trees have produced variable results, depending on methodologies and the communities examined. LeBlanc et al. (2007) detected differences in $16 \mathrm{~S}$ rRNA sequences extracted from soils associated with transformed spruce. However, Lamarche and Hamelin (2007) found no evidence for any impact of this transformation on rhizospheric diazotroph communities. In New Zealand field trials, some lines of Pinus radiata transformed with LEAFY and $n p t I I$ genes produced ephemeral differences in some $16 \mathrm{~S}$ rRNA profiles ( $\alpha$-Proteobacteria, Actinobacteria) detected with DGGE; however, overall effects on fungi and bacteria were judged to be insignificant (Lottman et al., 2010).

The proportion of $\mathrm{N}$-fixing bacteria was significantly greater in microcosms with low-tannin litter in our study. We attribute this to the presence of cellulosic substrate and nutrients available from decomposition. Several of the genera detected (Burkholderia, Sphingomonas) are reported to be diazotrophic endophytes of Populus trichocarpa and willow (Salix sitchensis) native to the Pacific Northwest (Doty et al., 2009). There was no such increase when added litter contained higher amounts of tannin; the proportion of $\mathrm{N}$-fixing bacteria remained similar to the lower proportion at the start of incubation. We attribute this result to an inhibitory effect of proanthocyanidins at higher (parental or transgenic) concentrations; phenolics, including tannins, were reported to inhibit $\mathrm{N}$-fixation in a study of decomposing litter from mangroves (Pelegrí and Twilley, 1998). It should be noted that an increase in the occurrence of $\mathrm{N}$-fixing organisms relates to the potential for $\mathrm{N}$-fixation. Our experiment detected the presence of $\mathrm{N}$-fixing organisms, but did not differentiate DNA from active vs. non-active $\mathrm{N}$-fixers. Our assumption is that abundance reflects functional behavior in this instance, but it should nevertheless be noted that actual functional behavior might not only directly reflect changes in overall abundance. Further experimentation, e.g., with mRNA or $\mathrm{N}$ assays, would be required to confirm functional impacts.

Impacts of litter on the proportion of nitrifiers were negligible. However, observed contrasts only cover an incubation period of $60 \mathrm{~d}$; ephemeral differences occurring before that point would not be captured in this analysis. Likewise, later differences due to differing decomposition rates (Preston et al., 2009a,b) or persistent inhibitory effects could also manifest. Increased sampling for a longer period would be needed to address these possibilities. While no significant changes in populations of nitrifiers, cellulose degraders, or phosphate solubilizers were detected, there is a possibility that minor changes could be detected with more extensive replication more precise identification, and targeting of other taxa within functional groups. For example, the study did not include a focus on archaea, and yet they may be dominant and more responsive in soils with low $\mathrm{N}$ (Leininger et al., 2006; Nicol et al., 2008; Huang et al., 2012; Zhalnina et al., 2012). Moreover, the functional response of microbial communities may be poorly reflected by population levels, or confounded by other functional responses or factors. Acidobacteria spp., for example, may possess the capacity to utilize cellulose and to reduce nitrates and nitrates (reversing nitrification) where soil nutrients are relatively low and soil moisture varies (Ward et al., 2009). They may also produce acid phosphatases (Koch et al., 2008) and dominate in soil zones where there is intense phosphate mobilization (Green et al., 2002). Factors such as soil carbon and $\mathrm{pH}$ may also affect Acidobacteria communities (Koch et al., 2008; Fierer et al., 2013). For overall functional impacts, shifts of species composing a functional group may therefore be as important as changes in numbers.

The impacts of proanthocyanidins on the bacterial communities observed here may have resulted from direct affects on bacterial growth, or indirect effects related to moss growth. For example, Bragina et al. (2012) have shown that patterns of $\alpha$-Proteobacteria and other bacterial taxa are affected by moss species. Effects of proanthocyanidins on moss growth would therefore also be likely to also have an impact on the community structure of microcosm soil bacteria.

DNA associated with Pucciniomycetes increased when litter was added, and most closely matched Eocronartium muscicola, a parasite of mosses (Aime et al., 2006). Boehm and McLaughlin (1988) reported that Eocronartium muscicola can arrest or supplant sporophyte growth. We attribute the growth of moss in the microcosms to the likely presence of moss protonema cells in the soils, before litter addition. The nearly significant increase of a putative moss parasite in litter with higher tannin levels suggests that the fungus may have been involved with the reduced moss growth shown in Figure 1. Further experimentation with these microcosms would be needed to understand how soil tannins might promote proliferation of the parasite.

The results show that condensed tannin content of litter may have implications for the rate of decomposition and soil nutrient cycling processes. Both natural genotypic variation and environmental factors influence tannin production, causing proanthocyanidin content to vary in natural poplar populations (Mansfield et al., 1999; Lindroth et al., 2002; Constabel and Lindroth, 2010). Even the highest tannin levels found in this experiment fell within the natural range of variation observed in forests (Preston et al., 2009a,b). The alteration in tannin levels due to the MYB 134 over-expression was thus in line with what could be expected from natural variation in proanthocyanidin content, and also with expected in situ variability. For the specific trait manipulated, i.e., tannin content, there would therefore be no environmental risks above and beyond those that would accompany conventional tree breeding efforts for this trait. Our work also found no evidence that there are additional environmental risks of the genetic transformation process itself for the soil microbe environment. It is important to note, however, that manipulation of specific traits, even if very targeted, can sometimes have unexpected secondary effects. For example, in the case of the MYB134 over-expressing plants, hightannin levels are reported to be accompanied by reduced salicinoid levels, likely due to internal metabolic trade-offs (Mellway et al., 2009). A full exploration of the effects of these phenolic antiherbivory compounds and other interrelated effects on soil microbes are beyond the scope of this work, we cannot rule out that at least some of the effects in the HP treatment might also be due to variable salicinoids or other factors. 
The microcosms used in this study only had incorporated soil. In further microcosm studies, it would be interesting to incorporate tree seedlings, understorey plants, EM fungi, earthworms, soil fauna, etc., to improve comparison to natural (in situ) conditions. A complete examination of how nutrient cycling phenomena work with respect to high-tannin litters is an important question for future study. The moss growing in these experiments likely had some impact via $\mathrm{N}$ uptake and immobilization (Weber and Van Cleve, 1984), fulfilling the role of understorey plants to some degree. Expanding the analyses to include sequences from incubated litterfree soil and incremental tannin measurements throughout the incubation period would also help to characterize responses. In future trials, improved risk assessments might also determine any effect of sterile vs. non-sterile litter, and include soils from plantations of the INRA 353-38 Populus tremula $\times$ tremuloides hybrid and/or variety of Populus spp. and hybrids.

The approach used in this study had the advantage of requiring fewer resources than, for example, 454 pyrosequencing or other next-generation sequencing methods. The use of 454 pyrosequencing could improve detection of some of the more subtle influences of litter on the soil communities, for example details on the occurrence of rare types. It could potentially help to clarify the observed differences in rarefaction rates for the $18 \mathrm{~S}$ signal, for example. However, the approach used in this study had the advantage of requiring fewer resources and avoiding saturation of the sequence dataset. DGGE, rDNA cloning and sequencing used here were sufficient to detect microbial dynamics in the microcosms. For nutrient cycling and other functions, the population dynamics of key, dominant species are likely the most relevant,

\section{REFERENCES}

Adamczyk, B., Kitunen, V., and Smolander, A. (2009). Polyphenol oxidase, tannase and proteolytic activity in relation to tannin concentration in the soil organic horizon under silver birch and Norway spruce. Soil Biol. Biochem. 5, 20852093. doi: 10.1016/j.soilbio.2009.07. 018

Aime, M. C., Matheny, P. B., Henk, D., Frieders, E. M., Nilsson, R. H., Piepenbring, M., et al. (2006). An overview of the higher level classification of Pucciniomycotina based on combined analyses of nuclear large and small subunit rDNA sequences. Mycologia 98, 896-905. doi: 10.3852/mycologia.98. 6.896

Altschul, S. F., Gish, W., Miller, W., Myers, E. W., and Lipman, D. J. (1990). Basic local alignment search tool. J. Mol. Biol. 215, 403-410. doi: 10.1016/S0022-2836(05)80360-2

Andreote, F. D., Carneiro, R. T., Salles, J. F., Marcon, J., Labate, C. A., Azevedo, J. L., et al. (2009). Culture-independent assessment of
Rhizobiales-related Alphaproteobacteria and the diversity of Methylobacterium in the rhizosphere and tus. Microb. Ecol. 57, 82-93. doi: 10.1007/s00248-008-9405-8

Anonymous (2001). Qiagen PCR Cloning Handbook for Qiagen PCR Cloning Kit. Mississauga, ON: Qiagen, Inc.

Boehm, E. W. A., and McLaughlin, D. J. (1988). Eocronartium muscicola: a basidiomycetous moss parasite exploiting gametophytic transfer cells. Can. J. Bot. 66, 762-770. doi: 10.1139/b88-113

Bolton, H., Fredrickson, J. K., Bentjen, S. A., Workman, D. J., Li, S. W., and Thomas, J. M. (1991). Field calibration of soil-core microcosms: fate of a genetically altered Rhizobacterium. Microb. Ecol. 21, 163-173. doi: 10.1007/BF02539151

Borneman, J., and Hartin, R. J. (2000). PCR primers that amplify fungal rRNA genes from environmental samples. Appl. Environ. Microbiol. 66, 4356-4436. doi: 10.1128/AEM.66.10.4356-4360.2000 rhizoplane of transgenic eucalyp-

unless a significant functional role can be demonstrated for the rare types.

Potential impacts (and therefore potential risks) associated with transgenic trees have been highlighted in various reports, but there are also potential risks in failing to respond to wide-scale anthropogenic impacts on forests. These may whether take the form of potential extirpations from recent pest introductions, or emerging threats such as climate change. Safe modification of tree traits offers the opportunity to streamline ongoing tree-breeding efforts to counter these threats. There is therefore a need to develop methods to assess the safety of genetically modified trees, even in areas where their commercial use is currently in question (McLean and Charest, 2000). Our work indicates that impacts of transgenic leaf litter on key forest soil communities can be effectively and safely evaluated in microcosms as a first step in characterizing the potential impacts (or lack thereof) that might be associated with a particular genetic modification. It also demonstrates the value of genetic transformations and microcosm research in exploring the genetic basis for ecological phenomena such as tannin impacts on soils.

\section{ACKNOWLEDGMENTS}

This research was supported by the Canadian Biotechnology Strategy Fund (Canadian Regulatory System for Biotechnology) and by the Canadian Forest Service (Genomics project). The authors thank Dr. Phyllis Dale, David Levy-Booth, Carrie Fischer, Emily Wong, Angie Li, and Tina Duan for their technical assistance and Dr. Robin Mellway for proanthocyanidin analysis. The authors also thank Scott Paper Company for access to field sites. They thank Dr. Isabel Leal, Dr. Jun-Jun Lui, Dr. Caroline Preston, Ms. Rona Sturrock, and Dr. Brian Titus for their reviews and suggestions.

Bradley, R. L., Titus, B. D., and Preston, C. M. (2000). Changes to mineral $\mathrm{N}$ cycling and microbial communities in black spruce humus after additions of (NH4)2SO4 and condensed tannins extracted from Kalmia angustifolia and balsam fir. Soil Biol. Biochem. 32, 1277 1240. doi: 10.1016/S0038-0717(00) 00039-0

Bragina, A., Berg, C., Cardinale, M., Shcherbakov, A., Chebotar, V., and Berg, G. (2012). Sphagnum mosses harbour highly specific bacterial diversity during their whole lifecycle. ISME J. 6, 802-813. doi: 10.1038/ismej.2011.151

Constabel, C. P., and Lindroth, R. I. (2010). "The impact of genomics on advances in herbivore defense and secondary metabolism in Populus," in Genetics and Genomics of Populus, eds S. Jannson, R. Bhaleaero, and A. Grover (New York: Spinger Verlag), 279-305.

Doty, S. L., Oakley, B., Xin, G., Kang, J. W., Singleton, G., Khan, Z., et al. (2009). Diazotrophic endophytes of native black cottonwood and willow. Symbiosis 47, 23-33. doi: 10.1007/BF03179967

Edgar, R. C. (2004). MUSCLE: multiple sequence alignment with high accuracy and high throughput. Nucleic Acids Res. 32, 1792-1797. doi: 10.1093/nar/gkh340

Fierer, N., Bradford, M. A., and Jackson, R. B. (2013). Toward an ecological classification of soil bacteria. Ecology 88, 1354-1364. doi: 10.1890/05-1839 Fierer, N., Schimel, J. P., Cates, R. G., and Zou, J. (2001). Influence of balsam poplar tannin fractions on carbon and nitrogen dynamics in Alaskan taiga floodplain soils. Soil Biol. Biochem. 33, 1827-1839. doi: 10.1016/S0038-0717(01)00111-0

Fortin, N., Beaumier, K. L., and Greer, C. W. (2004). Soil washing improves the recovery of total community DNA from polluted and high organic content sediments. J. Microbiol. Methods 56, 181-191. doi: 10.1016/j.mimet.2003.10.006

Gartland, K. M. A., Crow, R. M., Fenning, T. M., and Gartland, J. S. (2003). Genetically modified trees: production, properties, and potential. 
Arboric. Urban For. (J. Arboricult.) 29, 259-266.

Green, E. G., Macalady, J. L., and Banfield, J. F. (2002). Biogeochemical contributions to soil formation and landscape lowering. AGU Fall Meet. Abs. \#H12B-0929.

Halpin, C., Thain, S. C., Tilston, E. L., Guiney, E., Lapierre, C., and Hopkins, D. W. (2007). Ecological impacts of trees with modified lignin. Tree Genet. Genomes 3, 101-110. doi: 10.1007/s11295-006-0060-2

Hampp, R., Ecke, M., Schaeffer, C., Wallenda, T., Wingler, A., Kottke, I., et al. (1996). Axenic mycorrhization of wild type and transgenic hybrid aspen expressing T-DNA indoleacetic acid-biosynthetic genes. Trees 11, 59 64. doi: 10.1007/s004680050059

Hay, I., Morency, M., and Seguin, A. (2002). Assessing the persistence of DNA in decomposing leaves of genetically modified poplar trees. Can. J. For. Res. 32, 977-982. doi: 10.1139/x02-017

Holeski, L., Vogelzang, A., Stanosz, G., and Lindroth, R. L. (2009). Incidence of Venturia shoot blight in aspen (Populus tremuloides Michx.) varies with tree chemistry and genotype. Biochem. Syst. Ecol. 37, 139-145. doi: 10.1016/j.bse.2009.02.003

Howell, A. B., Vorsa, N., Der Marderosian, A., and Foo, L. Y. (1998). Inhibition of the adherence of P-fimbriated Escherichia coli to uroepithelial-cell surfaces by proanthocyanidin extracts from cranberries. N. Eng. J. Med. 339, 1085-1086. doi: 10.1056/ NEJM199810083391516

Huang, R., Wu, Y., Zhang, J., Zhong, W., Jia, Z., and Cai, Z. (2012). Nitrification activity and putative ammoniaoxidizing archaea in acidic red soils. J. Soils Sediments 12, 420-428. doi: 10.1007/s11368-011-0450-4

Huber, T., Faulkner, G., and Hugenholtz, P. (2004). Bellerophon: a program to detect chimeric sequences in multiple sequence alignments. Bioinformatics 20, 2317 2319. doi: 10.1093/bioinformatics/ bth226

Jansson, S., and Douglas, C. J. (2007). Populus: a model system for plant biology. Annu. Rev. Plant Biol. 58, 435-458. doi: 10.1146/annurev. arplant.58.032806.103956

Joanisse, G. D., Bradley, R. L., Preston, C. M., and Munson, A. D. (2007). Soil enzyme inhibition by condensed litter tannins may drive ecosystem structure and processes: the case of Kalmia angustifolia. New Phytol. 175, 535-546. doi: 10.1111/j.14698137.2007.02113.x
Kaldorf, M., Fladung, M., Muhs, H.J., and Buscot, F. (2002). Mycorrhizal colonization of transgenic aspen in a field trial. Planta 214, 653-660. doi: 10.1007/s004250100658

Kelley, C. C., and Spilsbury, R. H. (1939). Soil survey of the Lower Fraser Valley. Dominion of Canada Dept. of Agriculture, Ottawa, Publ. 650, Tech. Bull. 20.

Koch, I. H., Gich, F., Dunfield, P. F., and Overmann, J. (2008). Edaphobacter modestus gen. nov., sp. nov., and Edaphobacter aggregans sp. nov., acidobacteria isolated from alpine and forest soils. Int. J. Syst. Evol. Microbiol. 58, 1114-1122. doi: 10.1099/ijs.0.65303-0

Kraus, T. E., Zazoski, R. J., Dahlgren, R. A., Horwath, W. R., and Preston, C. M. (2004). Carbon and nitrogen dynamics in a forest soil amended with purified tannins from different plant species. Soil Biol. Biochem. 36, 309-321. doi: 10.1016/j.soilbio.2003.10.006

Krimsky, S., Wrubel, R. P., Naess, I. G., Levy, S. B., Wetzler, R. E., and Marshall, B. (1995). Standardized microcosms in microbial risk assessment. BioScience 45, 590-599. doi: 10.2307/1312763

Lamarche, J., and Hamelin, R. C. (2007). No evidence of impact of Bt-transgenic white spruce expressing the CrylAb toxin of Bacillus thuringiensis on rhizosphere diazotroph community. Appl. Environ. Microbiol. 73, 6577-6583. doi: 10.1128/AEM.00812-07

Lamarche, J., Stefani, F. O. P., Séguin, A., and Hamelin, R. C. (2011). Impact of endochitinase-trasformed white spruce on soil fungal communities under greenhouse conditions. FEMS Microbiol. Ecol. 76, 199-208. doi: 10.1111/j.1574-6941.2011.01041.x

LeBlanc, P. M., Hamelin, R. C. and Filion, M. (2007). Alteration of soil rhizosphere communities following genetic transformation of white spruce. Appl. Environ. Microbiol. 73, 4128-4134. doi: 10.1128/AEM.02590-06

Leininger, S., Urich, T., Schloter, M., Schwark, L., Qi, J., Nicol, G. W. et al. (2006). Archaea predominate among ammonia-oxidizing prokaryotes in soils. Nature 442, 806-809. doi: 10.1038/nature04983

Leple, J. C., Bonade-Bottino, M. Augustin, S., Pilate, G., Dumanois Le Tan, V., Delplanque, A., et al. (1995). Toxicity to Chrysomela tremulae (Coleoptera: Chrysomelidae) of transgenic poplars expressing a cysteine proteinase inhibitor. Mol. Breed. 1,319-328. doi: 10.1007/BF01248409
Lindroth, R. L., Osier, T. L., Barnhill, H. R. H., and Wood, S. A. (2002). Effects of genotype and nutrient availability on phytochemistry of trembling aspen (Populus tremuloides Michx.) during leaf senescence. Biochem. Syst. Ecol. 30, 297-307. doi: 10.1016/S0305-1978(01)00088-6

Lottman, J., O'Callaghan, M., Barid, D., and Walter, C. (2010). Bacterial and fungal communities in the rhizosphere of field-grown genetically modified pine trees (Pinus radiata D.). Environ. Biosafety Res. 9, 25-40. doi: 10.1051/ebr/2010007

Lozupone, C., and Knight, R. (2005). UniFrac: a new phylogenetic method for comparing microbial communities. Appl. Environ. Microbiol. 71, 8228-8235. doi: 10.1128/AEM. 71.12.8228-8235.2005

Machinet, G. E., Betrand, I., Chabbert, B., and Recous, S. (2009). Decomposition in soil and chemical changes of maize roots with genetic variations affecting cell wall quality. Eur. J. Soil Sci. 60, 176-185. doi: 10.1111/j.13652389.2008.01109.x

Madritch, M., Donaldson, J., and Lindroth, R. (2006). Genetic identity of Populus tremuloides litter influences decomposition and nutrient release in a mixed forest stand. Ecosystems 9, 528-537. doi: 10.1007/s10021-0060008-2

Madritch, M., and Hunter, M. (2003). Intraspecific litter diversity and nitrogen deposition affect nutrient dynamics and soil respiration. Oecologia 136, 124-128. doi: 10.1007/s00442-003-1253-0

Mansfield, J. (1999). Genotypic variation for condense tannin production in trembling aspen. Am. J. Bot. 86, 1154-1159. doi: 10.2307/2656979

Mansfield, J. L., Curtis, P. S., Zak, D. R., and Pregitzer, K. S. (1999). Genotypic variation for condensed tannin production in trembling aspen (Populus tremuloides, Salicaceae) under elevated $\mathrm{CO} 2$ and in high- and lowfertility soil. Am. J. Bot. 86, 1154 1159. doi: $10.2307 / 2656979$

Marvier, M. (2002). Improving risk assessment for nontarget safety of transgenic crops. Ecol. Appl. 12, 1119-1124. doi: 10.1890/1051-0761 (2002)012[1119:IRAFNS]2.0.CO;2

McGuire, K. L., and Treseder, K. K. (2009). Microbial communities and their relevance for ecosystem models: decomposition as a case study. Soil Biol. Biochem. 42, 529-535. doi: 10.1016/j.soilbio.2009.11.016

McLean, M. A., and Charest, P. J. (2000). The regulation of transgenic trees in North America. Silvae Genet. 49, 233-239.
Mellway, R. D., Tran, L. T., Prouse, M. B., Campbell, M. M., and Constabel, C. P. (2009). The wound-, pathogen-, and ultraviolet Bresponsive MYB134 gene encodes an R2R3 MYB transcription factor that regulates proanthocyanidin synthesis in poplar. Plant Physiol. 150, 924-941. doi: 10.1104/pp.109. 139071

Miranda, M., Ralph, S. G., Mellway, R., White, R., Heath, M. C., Bohlmann, J., et al. (2007). The transcriptional response of hybrid poplar (Populus trichocarpa x P. deltoides) to infection by Melampsora medusae leaf rust involves induction of flavonoid pathway genes leading to the accumulation of proanthocyanidins. Mol. Plant Microbe Int. 20, 816-831. doi: 10.1094/MPMI-20-70816

Morse, A. M., Cooke, J. E. K., and Davis, J. M. (2004). "Forest tree functional genomics," in Molecular Genetics and Breeding of Forest Trees, eds. S. Kumar and M. Fladung (Binghamton: Haworth Press), 3-17.

Newhouse, A. E., Schrodt, F., Liang, H., Maynard, C. A., and Powell, W. A. (2007). Transgenic American elm shows reduced Dutch elm disease symptoms and normal mycorrhizal colonization. Plant Cell Rep. 26, 977-987. doi: 10.1007/s00299-0070313-z

Nicol, G. W., Leininger, S., Schleper, C., and Prosser, J. I. (2008). The influence of soil $\mathrm{pH}$ on the diversity, abundance and transcriptional activity of ammonia oxidizing archaea and bacteria. Environ. Microbiol. 10, 2965-2978. doi: 10.1111/j.14622920.2008.01701.x

Norris, C. E., Preston, C. M., Hogg, K. E., and Titus, B. D. (2011). The influence of condensed tannin structure on rate of microbial mineralization and reactivity to chemical assays. J. Chem. Ecol. 37, 311-319. doi: 10.1007/s10886-011-9921-8

Oliver, K. L., Hamelin, R. C., and Hintz, W. E. (2008). Effects of transgenic hybrid aspen overexpressing polyphenol oxidase on rhizosphere diversity. Appl. Environ. Microbiol. 74, 5340-5348. doi: 10.1128/AEM.02836-07

Pasonen, H.-L., Degefu, Y., Brumós, J., Lohtander, K., Pappinen, A., Timonen, S., et al. (2005). Transgenic Betula pendula expressing sugar beet chitinase IV forms normal ectomycorrhizae with Paxillus involutus in vitro. Scand. J. For. Res. 20, 385392. doi: 10.1080/0282758050025 1432 
Pelegrí, S. P., and Twilley, R. R. (1998). Heterotrophic nitrogen fixation (acetylene reduction) during leaf-litter decomposition of two mangrove species from South Florida, USA. Mar. Biol. 131, 53-61. doi: 10.1007/s002270050296

Peña, L., and Seguin, A. (2001). Recent advances in the genetic transformation of trees. Trends Biotechnol. 19, 500-506. doi: 10.1016/S01677799(01)01815-7

Porter, L. J., Hrstich, L. N., and Chan, B. G. (1986). The conversion of procyanidins and prodelphinidins to cyanidin and delphinidin. Phytochemistry 25, 223-230. doi: 10.1016/S0031-9422(00)94533-3

Preston, C. M., Nault, J. R., and Trofymow, J. A. (2009a). Chemical changes during 6 years of decomposition of 11 litters in some Canadian forest sites. Part 2. 13C Abundance, SolidState 13C NMR Spectroscopy and the Meaning of "Lignin". Ecosystems 12, 1078-1102. doi: 10.1007/s10021009-9267-z

Preston, C. M., Nault, J. R., Trofymow, J. A., Smyth, C., and CIDET Working Group. (2009b). Chemical changes during 6 years of decomposition of 11 litters in some Canadian forest sites. Part 1. Elemental composition, tannins, phenolics, and proximate fractions. Ecosystems 12, 1053-1077. doi: 10.1007/s10021-009-9266-0

Quinsey, S., Stettler, R. F., Heilman, P. E., Delany, D., Fenn, R., Ager, A., et al. (1991). Pedigree Clone Register. University of Washington/Washington State University Poplar Research Program. College of Forest Resources, University of Washington, Seattle.

R Development Core Team. (2005). R: A Language and Environment for Statistical Computing. Vienna: R Foundation for Statistical Computing.

Scalbert, A. (1991). Antimicrobial properties of tannins. Phytochemistry 30, 3875-3883. doi: 10.1016/00319422(91)83426-L

Schimel, J. P., Cates, R. G., and Ruess, R. (1998). The role of balsam poplar secondary chemicals in controlling soil nutrient dynamics through succession in the Alaska taiga. Biogeochemistry 42, 221-234. doi: 10.1023/A:1005911118982

Schloss, P. D., Westcott, S. L., Ryabin, T., Hall, J. R., Hartmann, M., Hollister, E. B., et al. (2009). Introducing mothur: open-source, platformindependent, community-supported software for describing and comparing microbial communities. Appl. Environ. Microbiol. 75, 7537-7541. doi: 10.1128/AEM.01541-09

Schweitzer, J. A., Bailey, J. K., Fischer, D. G., LeRoy, C. J., Lonsdorf, E. V., Whitham, T. G., et al. (2008). Plant-soil-microorganism interactions: heritable relationship between plant genotype and associated soil microorganisms. Ecology 89, 773-781. doi: 10.1890/07-0337.1

Schweitzer, J. A., Bailey, J. K., Rehill, B. J., Martinsen, G. D., Hart, S. C., Lindroth, R. L., et al. (2004). Genetically based trait in a dominant tree affects ecosystem processes. Ecol. Lett. 7, 127-134. doi: 10.1111/j.14610248.2003.00562.x

Seppänen, S.-K., Pasonen, H.-L., Vauramo, S., Vahala, J., Toikka, M. Kilpeläinen, I., et al. (2007). Decomposition of the leaf litter and mycorrhiza forming ability of silver birch with a genetically modified lignin biosynthesis pathway. Appl. Soil Ecol. 36, 100-106. doi: 10.1016/j. apsoil.2006.12.002

Stanton, B., Eaton, J., Johnson, J., Rice, D., Schuette, B., and Moser, B. (2002). Hybrid poplar in the Pacific Northwest. The effects of marketdriven management. J. For. 100, 28-33.

Stefani, F. O. P., Mancalvo, J.-M., Séguin, A., Bérubé, J. A., and Hamelin, R. C. (2009). Impact of an 8-year-old transgenic poplar plantation on the ectomycorrhizal fungal community. Appl. Environ. Microbiol. 75, 75277536. doi: 10.1128/AEM.01120-09

Stefani, F. O. P., Tanguay, P., Pelletier, G., Piché, Y., and Hamelin, R. C. (2010). Impact of endochitinasetransformed white spruce on soil fungal biomass and ectendomycorrhizal symbiosis. Appl. Envrion. Microbiol. 76, 2607-2614. doi: 10.1128/AEM. 02807-09
Tamura, K., Dudley, J., Nei, M., and Kumar, S. (2007). MEGA4: Molecular Evolutionary Genetics Analysis (MEGA) software version 4.0. Mol. Biol. Evol. 24, 1596-1599. doi: 10.1093/molbev/msm092

Teuben, A., and Verhoef, H. A. (1992). Direct contribution by soil arthropods to nutrient availability through body and faecal nutrient content. Biol. Fertil. Soils 14, 71-75. doi: 10.1007/BF00336253

Triebwasser, D. J., Tharayil, N., Preston, C. M., and Gerard, P. D. (2012) The susceptibility of soil enzymes to inhibition by leaf litter tannins is dependent on the tannin chemistry, enzyme class and vegetation history. New Phytol. 196, 1122 1132. doi: 10.1111/j.1469-8137.2012. 04346.x

Vainio, E. J., Hallaksela, A. M., Lippone, K., and Hantula, J. (2005). Direct analysis of ribosomal DNA in denaturing gradients: application on the effects of Phlebiopsi gigantea treatment on fungal communities of conifer stumps. Mycol. Res. 109, 103-114. doi: 10.1017/ S0953756204001406

van Frankenhuyzen, K., and Beardmore, T. (2004). Current status and environmental impact of transgenic forest trees. Can. J. For. Res. 34, 1163-1180. doi: 10.1139/ x04-024

Vauramo, S., Pasonen, H. L., Pappinen, A., and Setala, H. (2006). Decomposition of leaf litter from chitinase transgenic silver birch (Betula pendula) and effects on decomposer populations in a field trial. Appl. Soil Ecol. 32, 338-349. doi: 10.1016/ j.apsoil.2005.07.007

Wang, Q., Garrity, G. M., Tiedje, J. M., and Cole, J. R. (2007). Naïve Bayesian classifier for rapid assignment of rRNA sequences into the new bacterial taxonomy. Appl. Environ. Microbiol. 73, 5261-5267. doi: 10.1128/AEM.00062-07

Ward, N. L., Challacombe, J. F., Janssen, P. H., Henrissat, B., Coutinho, P. M. Wu, M., et al. (2009). Three genomes from the phylum Acidobacteria provide insight into the lifestyles of these microorganisms in soils. Appl. Environ. Microbiol. 75, 2046-2056. doi: 10.1128/AEM.02294-08

Weber, M. G., and Van Cleve, K. (1984). Nitrogen transformations in feather moss and forest floor layers of interior Alaska black spruce ecosystems. Can. J. For. Res. 14, 278-290. doi: 10.1139/x84-053

Witham, T. G., Bailey, J. K., Schweitzer, J. A., Shuster, S. M., Bangert, R. K., LeRoy, C. J., et al. (2006). A framework for community and ecosystem genetics: from genes to ecosystems. Nat. Rev. Genet. 7, 510-523. doi: $10.1038 / \mathrm{nrg} 1877$

Zhalnina, K., de Quadros, P. D., Carmargo, F. A. O., and Triplett, E. W. (2012). Drivers of archaeal ammonia-oxidizing communities in soil. Front. Microbiol. 3:210. doi: $10.3389 /$ fmicb. 2012.00210

Conflict of Interest Statement: The authors declare that the research was conducted in the absence of any commercial or financial relationships that could be construed as a potential conflict of interest.

Received: 24 April 2013; accepted: 09 September 2013; published online: 26 September 2013.

Citation: Winder RS, Lamarche J, Constabel CP and Hamelin RC (2013) The effects of high-tannin leaf litter from transgenic poplars on microbial communities in microcosm soils. Front. Microbiol. 4:290. doi: 10.3389/fmicb.2013. 00290

This article was submitted to Terrestrial Microbiology, a section of the journal Frontiers in Microbiology.

Copyright (c) 2013 Winder, Lamarche, Constabel and Hamelin. This is an openaccess article distributed under the terms of the Creative Commons Attribution License (CC BY). The use, distribution or reproduction in other forums is permitted, provided the original author(s) or licensor are credited and that the original publication in this journal is cited, in accordance with accepted academic practice. No use, distribution or reproduction is permitted which does not comply with these terms. 